\title{
Neisseria meningitidis rifampicin resistant strains: analysis of protein differentially expressed
}

\author{
Arianna Neri ${ }^{1}$, Giuseppina Mignogna ${ }^{2}$, Cecilia Fazio ${ }^{1}$, Alessandra Giorgi ${ }^{2}$, Maria Eugenia Schininà ${ }^{2}$, Paola Stefanelli $^{{ }^{*}}$
}

\begin{abstract}
Background: Several mutations have been described as responsible for rifampicin resistance in Neisseria meningitidis. However, the intriguing question on why these strains are so rare remains open. The aim of this study was to investigate the protein content and to identify differential expression in specific proteins in two rifampicin resistant and one susceptible meningococci using two-dimensional electrophoresis (2-DE) combined with mass spectrometry.

Results: In our experimental conditions, able to resolve soluble proteins with an isoelectric point between 4 and 7 , twenty-three proteins have been found differentially expressed in the two resistant strains compared to the susceptible. Some of them, involved in the main metabolic pathways, showed an increased expression, mainly in the catabolism of pyruvate and in the tricarboxylic acid cycle. A decreased expression of proteins belonging to gene regulation and to those involved in the folding of polypeptides has also been observed. 2-DE analysis showed the presence of four proteins displaying a shift in their isoelectric point in both resistant strains, confirmed by the presence of amino acid changes in the sequence analysis, absent in the susceptible.

Conclusions: The analysis of differentially expressed proteins suggests that an intricate series of events occurs in $N$. meningitidis rifampicin resistant strains and the results here reported may be considered a starting point in understanding their decreased invasion capacity. In fact, they support the hypothesis that the presence of more than one protein differentially expressed, having a role in the metabolism of the meningococcus, influences its ability to infect and to spread in the population. Different reports have described and discussed how a drug resistant pathogen shows a high biological cost for survival and that may also explain why, for some pathogens, the rate of resistant organisms is relatively low considering the widespread use of a particular drug. This seems the case of rifampicin resistant meningococci.
\end{abstract}

\section{Background}

Management of meningococcal disease requires immediate treatment of patients and chemoprophylaxis of contacts. For the latter, rifampicin is the most frequently used antibiotic. However, although it has been utilized routinely worldwide for more than 30 years, few cases of rifampicin resistant meningococci have been reported [1]. This scarce diffusion is intriguing and the reduced virulence of these strains in terms of the bacterium's survival in the bloodstream of mice, as shown in an in vivo model, suggests a major biological cost for the microorganism [2].

\footnotetext{
* Correspondence: paola.stefanelli@iss.it

'Department of Infectious, Parasitic and Immune-mediated Diseases, Istituto

Superiore di Sanità, Viale Regina Elena 299, 00161 Rome, Italy

Full list of author information is available at the end of the article
}

The resistance phenotype is correlated with a set of mutations in the $r p o B$ gene, encoding the $\beta$ subunit of RNA polymerase, resulting in amino acid substitutions at one of the following codons: Asp542, Ser548, His552, Ser557, Gly560 [3-6]. Moreover, other mechanisms have been described in both Neisseria meningitidis and in Neisseria gonorrhoeae $[7,8]$, i.e. resistance to diverse hydrophobic agents, including Triton $\mathrm{X}$, is associated with mutations in the $m$ trR gene and in its promoter $[7,9,10]$. Overall, in other species, such as Mycobacterium tuberculosis, resistance was not related to any changes in the rpoB gene in around 5\% of clinical rifampicin resistant isolates [11]. Rifampicin binds to DNAdependent RNA polymerase and inhibits initiation of RNA synthesis which is not a mechanism of action shared with other antibiotics. This effect on RNA polymerase appears to result from drug binding in the 
polymerase subunit deep within the DNA/RNA channel where direct blocking of the elongating RNA can occur.

Little is known of the protein expression of $N$. meningitidis resistant to rifampicin and how this contributes to pathogenesis. In the present study, soluble proteins of two rifampicin resistant and one susceptible meningococci isolated in Italy, and previously described [5], were analysed by two-dimensional electrophoresis (2-DE) combined with mass spectrometry (MALDI-ToF). The method has been chosen because it is a comprehensive approach to investigate the protein content of a pathogen [12], and in this context helpful to identify differential expression in specific proteins in particular in rifampicin resistance meningococci.

\section{Methods}

\section{Bacterial strains and bacterial proteins extraction}

Two rifampicin resistant $\left(\mathrm{RIF}^{\mathrm{R}}\right) 870$ and 901 strains and one rifampicin susceptible $\left(\mathrm{RIF}^{\mathrm{S}}\right) 1958$ serogroup $\mathrm{C}$ meningococci were analysed. The resistant strains showed two already described [5] mutations in the $r p o B$ gene, the Asp542Val and the His552Tyr. Strain 870 had caused fatal septicaemia in a 34 year-old man and strain 901, meningitis in a 1 year-old infant. The RIF $^{S} 1958$ invasive strain was responsible for septicaemia in an infant aged 2, and since the absence of mutations in the rрo $B$ gene, was chosen as control strain.

Bacterial protein extraction was performed according to the protocol previously described [13], with some modifications. In particular, the confluent bacterial growth was scraped from the plates and washed twice with PBS, suspended in $5 \mathrm{ml}$ of lysis buffer $(500 \mathrm{mM} \mathrm{NaCl}, 10 \mathrm{mM}$ EDTA, $50 \mathrm{mM}$ Tris $\mathrm{pH} 8.0$ ) containing $0.3 \mathrm{mg} / \mathrm{ml}$ protease inhibitor (CompleteMini, Roche Diagnostic, Mannheim, Germany) and 150U DNase I (Roche Diagnostic).

The sample analysed by 2-DE approach corresponds to the cytosolic fraction, in which most of the proteins involved in the metabolic pathway and in essential biological processes have been described in bacteria.

\section{Two-dimensional gel electrophoresis}

Before electrophoresis an aliquot of protein extract corresponding to $350 \mu \mathrm{g}$ of each sample was precipitated by adding nine volumes of cold-ethanol and keeping at $-20^{\circ} \mathrm{C}$ overnight. Samples were centrifuged at $14.000 \mathrm{~g}$ for $15 \mathrm{~min}$ at $4^{\circ} \mathrm{C}$ and pellets were dried and then dissolved in $185 \mu \mathrm{l}$ of a rehydration buffer containing $7 \mathrm{M}$ urea, $2 \mathrm{M}$ thiourea, 2\% w/v CHAPS, $50 \mathrm{mM}$ DTT, $0.2 \%$ $\mathrm{v} / \mathrm{v}$ Bio-Lytes ${ }^{\mathrm{Tm}} \mathrm{pH}$ range 3-10. Each sample was loaded on an 11-cm precast Immobiline strip with a linear $\mathrm{pH}$ 4-7 gradient and three replica maps were performed. First- and second-dimension electrophoresis, and image analysis were carried out as already described by Mignogna et al. [13].

\section{Protein identification}

Spots selected according to the procedure previously described [13], were manually excised from gels and digested with trypsin. Digestion was performed at $37^{\circ} \mathrm{C}$ overnight. Briefly, after several destaining steps using 50 $\mathrm{mM}$ ammonium bicarbonate (15 $\mathrm{min}), 50 \%$ acetonitrile in $50 \mathrm{mM}$ ammonium bicarbonate $(10 \mathrm{~min})$ and $100 \%$ acetonitrile (15 min), subsequently, about $100 \mathrm{ng}$ of trypsin (Trypsin Gold, Mass Spectrometry Grade, Promega, Madison, WI, USA), solubilised in $10 \mu \mathrm{l}$ of a 25 $\mathrm{mM}$ ammonium bicarbonate digestion buffer, were added to vacuum-dried gel.

An aliquot $(1 \mu \mathrm{l})$ of each mixture peptide was mixed with the same volume of $\alpha$-cyano-4-hydroxy-trans-cinnamic acid matrix solution $(5 \mathrm{mg} / \mathrm{ml})$ in $70 \%$ acetonitrile containing $0.1 \%$ TFA (v/v) for MALDI-ToF analysis, performed in a Voyager-DE STR instrument (Applied Biosystems, Framingham, MA) equipped with a $337 \mathrm{~nm}$ nitrogen laser and operating in reflector mode. Mass data were obtained by accumulating several spectra from laser shots with an accelerating voltage of $20 \mathrm{kV}$. Two tryptic autolytic peptides were used for the internal calibration $(\mathrm{m} / \mathrm{z} 842.5100$ and 2807.3145).

Identification by peptide mass fingerprint (PMF), was performed using the Mascot search engine version 2.2 [14] against NCBlnr database (10386837 sequences). Up to one missed cleavage, $50 \mathrm{ppm}$ measurement tolerance, oxidation at methionine (variable modification) and carbamidomethyl cysteine (fixed modification) were considered. Post-translational modifications were not taken into account. Identifications were validated when the probability-based Mowse protein score was significant according to Mascot [15].

\section{Statistical analysis of 2-DE maps}

For gel comparison, a statistical approach was applied when determining differentially expressed proteins using the PDQuest software (version 7.2.0, BioRad). Student's $t$ test was performed with $90 \%$ significance level to determine which proteins were differentially expressed between the susceptible and resistant strain. Thresholds for assigning differential expression between the two pools were setat a minimum 2-fold change for up-regulation and 0.5-fold for down-regulation. This fold change threshold was chosen to obtain significant changes in protein expression. To minimize variation due to experimental factors, the intensity of each spot was normalized on the basis of the total integrated optical density for the examined gel.

\section{Sequence analysis of the genes encoding the four shifted proteins}

Chromosomal DNAs were extracted by using the QIAamp DNA mini kit (Qiagen, Hilden, Germany) 
according to the manufacturer's instruction. The encoding genes for the four shifted proteins of the meningococcal isolates were amplified by PCR and sequenced with primers designed on conservative regions of corresponding genes from $N$. meningitidis FAM18 (NCBI accession number AM421808) (Table 1). All reactions were carried out with 100ng of purified chromosomal DNA, $5 \mu$ l of $10 \times$ reaction buffer, 0.01 $\mathrm{mM}$ of dNTP solution (Finnzymes, Finland), 2.5U HotStartTaq (Qiagen), 25pmol of each primer and sterile water to a final volume of $50 \mu \mathrm{l}$. Three different cycle conditions, changing for the annealing temperatures, were set up for the putative oxidoreductase, putative phosphate acyltransferase, putative zinc-binding alcohol dehydrogenase genes, respectively. In particular, $95^{\circ} \mathrm{C}$ for 15 minutes (hot-start); 30 cycles of $95^{\circ} \mathrm{C}$ for 30 seconds, $54^{\circ} \mathrm{C}-55^{\circ} \mathrm{C}-58^{\circ} \mathrm{C}$ for 30 seconds, and $72^{\circ} \mathrm{C}$ for 1 minute; and a final extension reaction at $72^{\circ} \mathrm{C}$ for 7 minutes.

Cycle conditions for the isocitrate dehydrogenase gene were set at $95^{\circ} \mathrm{C}$ for 15 minutes (hot-start); 30 cycles of $95^{\circ} \mathrm{C}$ for 30 seconds, $58^{\circ} \mathrm{C}$ for 30 seconds, and $72^{\circ} \mathrm{C}$ for 2 minutes; a final extension reaction at $72^{\circ} \mathrm{C}$ for 7 minutes.

The PCR products were analysed using the BLAST program http://www.ncbi.nlm.nih.gov/BLAST/; amino acid sequences were aligned using the ClustalW program http://www.ebi.ac.uk/clustalw/.

\section{Analysis of $N$. meningitidis rifampicin resistant and susceptible strains growth curves}

Meningococcal strains were incubated overnight on GC agar base (Oxoid, Basingstoke, UK) plates at $37^{\circ} \mathrm{C}$ with $5 \% \mathrm{CO}_{2}$. Isolated colonies were inoculated in $4 \mathrm{ml} \mathrm{GC}$ broth plus rifampicin slightly stirring. The broth suspensions were immediately adjusted to an initial $\mathrm{OD}_{600}$ of 0.08 and the growth was measured by reading optical density (OD) every $60 \mathrm{~min}$.

The $\operatorname{RIF}^{\mathrm{R}}$ strains were grown on plates with $50 \mu \mathrm{g} / \mathrm{ml}$ of rifampicin. Each growth curve was repeated three times.

\section{Results}

Analysis of protein expression by 2-DE

The 2-DE gels were performed in three replicates and variations in spot intensity were confirmed by statistical analysis. Representative 2-DE maps of the two $\operatorname{RIF}^{\mathrm{R}} 870$ and 901 strains and one RIF ${ }^{\mathrm{S}} 1958$, are reported in figure $1 \mathrm{~A}$. The number of detected spots was in a range of 320 to 450 for all replicates.

As shown in figure $1 \mathrm{~A}$, there was a high similarity in protein pattern among the resistant and susceptible strains, with the majority of proteins ranging from $\mathrm{pI} 4$ to 6 and with a molecular weight from 6000 to 195000 Da.

Protein identification by 2-DE gels and relative expression data were compared using PDQuest software; spots with a minimum of 2 -fold change were chosen to define an up-expressed protein and 0.5-fold to define a downexpressed protein.

A total of twenty-three spots were found to be differentially expressed in both rifampicin resistant strains compared to the susceptible; all of them were subjected to the peptide mass fingerprinting (PMF) by MALDIToF analysis for protein identification. We performed the same analysis also on two isogenic rifampicin resistant meningococci mutants: the reference strain $N$. meningitidis serogroup B MC58 and one clinical isolate (data not shown).

Table 2 shows the functional classification of 23 upand down-expressed proteins according to Universal Protein Knowledgebase (UniProtKB) database [16].

Proteins belonging to the carbohydrate metabolism and the enzymes involved in the reactions of the tricarboxylic cycle (TCA) resulted up-expressed: in particular, the phosphenolpyruvate synthase [A1KSM6], the pyruvate dehydrogenase subunit E1 [A1KUG5], the glutamate dehydrogenase [A1KVB4], together with the isocitrate dehydrogenase [A1KTJ0], the succinyl-CoA synthetase subunit beta [A1KTM6] and the aconitate hydratase [A9M175]. Four proteins belonging to different metabolic pathways and those responsible for ATP production were down-expressed in both resistant

Table 1 Primers for amplification and sequence analyses of genes encoding the four shifted proteins found in rifampicin resistant meningococci

\begin{tabular}{|c|c|c|}
\hline Primer & Sequence $\left(5^{\prime} \rightarrow 3^{\prime}\right)$ & Protein encoded (Locus tag) \\
\hline ADZ-f & ${ }^{576170}$ GCGTTTCAGACGGCATTTGT ${ }^{576189 *}$ & putative zinc-binding alcohol dehydrogenase (NMC0547) \\
\hline ADZ-r & ${ }^{577320}$ GCCAGATTCAGACGGTATTCC ${ }^{577300 *}$ & \\
\hline ICD-f & ${ }^{893762}$ ACGACGAATGTTCAGACGG ${ }^{893780 *}$ & isocitrate dehydrogenase (NMC0897) \\
\hline ICD-r & ${ }^{896097}$ TGCCATAATAGCCACGCAC ${ }^{896079 *}$ & \\
\hline PTA-f & ${ }^{607259}$ AAGCCGTTTGTCAGCCTT ${ }^{607276 *}$ & putative phosphate acyltransferase Pta (NMC0575) \\
\hline PTA-r & ${ }^{608401}$ CGGGCGTATTGGAAGGTTT ${ }^{608383 *}$ & \\
\hline POX-f & ${ }^{445746}$ AAAGCCGGATAAGTGGGAAC ${ }^{445765 *}$ & putative oxidoreductase (NMC0426) \\
\hline
\end{tabular}

* the position referring to the corresponding accession number of $N$. meningitidis strain FAM18, accession number AM421808. 


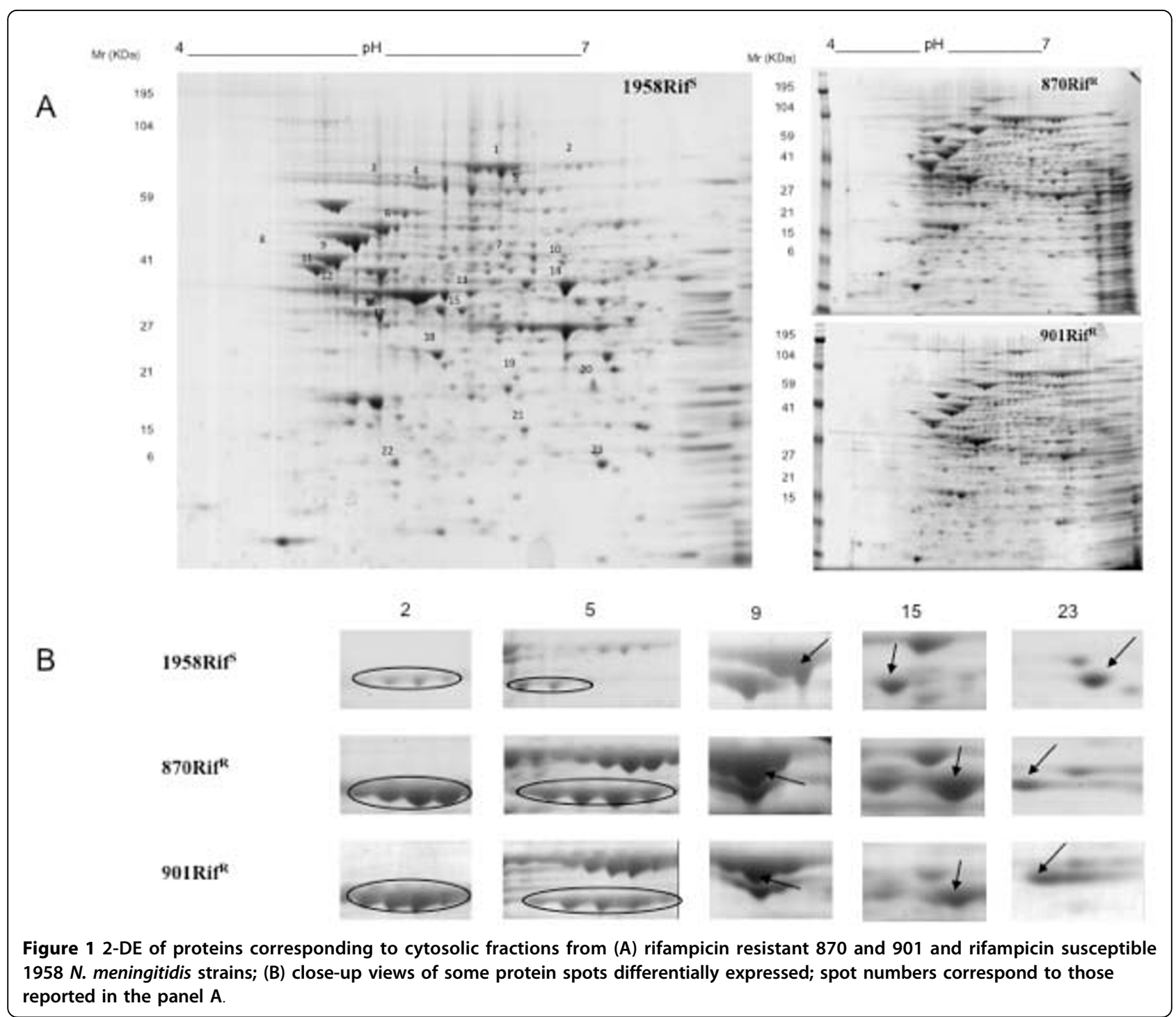

strains: the malate quinone oxidoreductase [A1KWH2], the enolase [A1KUB6], the putative zinc-binding alcohol dehydrogenase [A1KSL2], the carboxyphosphonoenol pyruvate phosphonomutase [A9M2G6] and the F0F1 ATP synthase subunit $\alpha$ [A9M121 (Table 2).

A second group of proteins is involved in the regulation of the gene expression: the elongation factor $G$ [A1KRH0], the transcription elongation factor NusA [C9WY90], and the DNA-directed RNA polymerase subunit $\alpha$ [A1KRJ9] were up-expressed. On the contrary, the DNA-binding response regulator [A9M2D6], involved in the transcription, the trigger factor [A1KUE0] involved in protein export, the $60 \mathrm{kDa}$ chaperonin [A1KW52], that prevents misfolding and promotes the refolding of polypeptides, and the peptidyl-prolyl cis-trans isomerase [A9M3M5], which accelerates the folding of proteins, were down-expressed.
The cell division protein [A1KVK9], the septum sitedetermining protein MinD [A9M3T7], the malonyl-CoAacyl carrier protein transacylase [A1KRY7] and the putative oxidoreductase [A9M1W2], also resulted down-expressed.

Four of the 23 listed proteins in the Table2 had a different $\mathrm{pI}$ in both the resistant strains. The difference in the $\mathrm{pI}$ was well visualised in the 2-DE gels. As shown in figure $1 \mathrm{~B}$, the isocitrate dehydrogenase (spot 5) and the putative zinc-binding alcohol dehydrogenase (spot 15) were shifted to a more basic pI, while the putative phosphate acetyltransferase (spot 9) and the putative oxidoreductase (spot 23) were shifted to a more acidic pI.

\section{Sequence analysis of the genes encoding the shifted proteins}

The four genes encoding proteins with a different $\mathrm{pI}$ were sequenced. In particular, NMC0426, NMC0547, 
Table $\mathbf{2}$ List of the $\mathbf{2 3}$ differentially expressed proteins found in rifampicin resistant Neisseria meningitidis strains

\begin{tabular}{|c|c|c|c|c|c|c|c|c|}
\hline Spot $n$ & Protein name (gene) $^{a}$ & $\begin{array}{l}\text { Protein } \\
\text { accession } \\
\text { number }\end{array}$ & $\begin{array}{l}\text { Ordered } \\
\text { Locus } \\
\text { Name }\end{array}$ & $\begin{array}{c}\text { Sequence } \\
\text { coverage } \\
\%\end{array}$ & $\begin{array}{l}\text { Mowse } \\
\text { Score }\end{array}$ & $\mathrm{MW}_{\mathrm{t}} / \mathrm{pl}_{\mathrm{t}}$ & $\begin{array}{l}\text { Expression } \\
\text { level }^{c}\end{array}$ & $\begin{array}{l}\text { UniProtKB } \\
\text { Functional classification }{ }^{d}\end{array}$ \\
\hline 1 & Aconitate hydratase (acnB) & A1KUZ6 & NMC1492 & 51 & 403 & $93412 / 5.38$ & up & $\begin{array}{l}\text { Carbohydrate metabolism: } \\
\text { TCA cycle }\end{array}$ \\
\hline 2 & $\begin{array}{l}\text { Piruvate dehydrogenase } \\
\text { subunit E1 (aceE) }\end{array}$ & A1KUG5 & NMC1278 & 53 & 426 & $99915 / 5.60$ & up & $\begin{array}{l}\text { Carbohydrate metabolism: } \\
\text { pyruvate metabolism }\end{array}$ \\
\hline 3 & $\begin{array}{l}\text { Putative } \\
\text { phosphoenolpyruvate } \\
\text { synthase (ppsA) }\end{array}$ & A1KSM6 & NMC0561 & 26 & 165 & $87128 / 6.01$ & up & $\begin{array}{l}\text { Carbohydrate metabolism: } \\
\text { pyruvate metabolism }\end{array}$ \\
\hline 4 & Elongation factor G (fusA) & $\mathrm{A} 1 \mathrm{KRHO}$ & NMC0127 & 30 & 245 & $77338 / 5.08$ & up & $\begin{array}{l}\text { Genetic Information } \\
\text { Processing: protein } \\
\text { synthesis }\end{array}$ \\
\hline 5 & Isocitrate dehydrogenase (icd) & A1KTJO & NMC0897 & 27 & 229 & $80313 / 5.53$ & $u^{*}$ & $\begin{array}{l}\text { Carbohydrate metabolism: } \\
\text { TCA cycle }\end{array}$ \\
\hline 6 & 60 kDa chaperonin (groL) & A1KW52 & NMC1948 & 41 & 206 & $57535 / 4.90$ & down & $\begin{array}{l}\text { Genetic Information } \\
\text { Processing: protein folding }\end{array}$ \\
\hline 7 & $\begin{array}{l}\text { ATP synthase subunit } \alpha \\
(\operatorname{atpA})\end{array}$ & A1KW13 & NMC1908 & 62 & 281 & $55481 / 5.50$ & down & $\begin{array}{l}\text { Energy metabolism: } \\
\text { oxidative phosphorilation }\end{array}$ \\
\hline 8 & $\begin{array}{l}\mathrm{N} \text { utilisation substance } \\
\text { protein } \mathrm{A} \text { (nus } \mathrm{A} \text { ) }\end{array}$ & A1KV50 & NMC1556 & 71 & 426 & $55745 / 4.54$ & up & $\begin{array}{l}\text { Genetic Information } \\
\text { Processing: protein } \\
\text { synthesis }\end{array}$ \\
\hline 9 & $\begin{array}{l}\text { Putative phosphate } \\
\text { acyltransferase (NMC0575) }\end{array}$ & A1KSN9 & NMC0575 & 47 & 263 & $57551 / 5.47$ & $u^{*}$ & $\begin{array}{l}\text { Carbohydrate metabolism: } \\
\text { propanoate metabolism }\end{array}$ \\
\hline 10 & $\begin{array}{l}\text { Probable malate:quinone } \\
\text { oxidoreductase (mqo) }\end{array}$ & $\mathrm{A} 1 \mathrm{KWH} 2$ & NMC2076 & 36 & 178 & $54091 / 5.58$ & down & $\begin{array}{l}\text { Carbohydrate metabolism: } \\
\text { TCA cycle }\end{array}$ \\
\hline 11 & Trigger factor (tig) & A1KUE0 & NMC1250 & 51 & 209 & $48279 / 4.76$ & down & $\begin{array}{l}\text { Genetic Information } \\
\text { Processing: protein folding }\end{array}$ \\
\hline 12 & Enolase (eno) & A1KUB6 & NMC1220 & 25 & 129 & $46319 / 4.78$ & down & $\begin{array}{l}\text { Carbohydrate metabolism: } \\
\text { glycolysis }\end{array}$ \\
\hline 13 & Cell division protein (ftsA) & A1KVK9 & NMC1738 & 40 & 132 & $44348 / 5.33$ & down & $\begin{array}{l}\text { Genetic Information } \\
\text { Processing: cell division }\end{array}$ \\
\hline 14 & $\begin{array}{l}\text { Glutamate dehydrogenase } \\
\text { (gdhA) }\end{array}$ & A1KVB4 & NMC1625 & 54 & 221 & $48731 / 5.80$ & up & $\begin{array}{l}\text { Energy metabolism: amino } \\
\text { acid metabolism }\end{array}$ \\
\hline 15 & $\begin{array}{l}\text { Putative zinc-binding alcohol } \\
\text { dehydrogenase (NMC0547) }\end{array}$ & A1KSL2 & NMC0547 & 38 & 235 & $38283 / 5.32$ & down* & $\begin{array}{l}\text { Carbohydrate metabolism: } \\
\text { butanoate metabolism }\end{array}$ \\
\hline 16 & $\begin{array}{l}\text { Succinyl-CoA ligase [ADP- } \\
\text { forming] subunit beta (sucC) }\end{array}$ & A1KTM6 & NMC0935 & 26 & 125 & $41567 / 5.01$ & up & $\begin{array}{l}\text { Carbohydrate metabolism: } \\
\text { TCA cycle }\end{array}$ \\
\hline 17 & $\begin{array}{l}\text { DNA-directed RNA } \\
\text { polymerase subunit } \alpha(r p o A)\end{array}$ & A1KRJ9 & NMC0158 & 41 & 184 & $36168 / 4.94$ & up & $\begin{array}{l}\text { Genetic Information } \\
\text { Processing: transcription }\end{array}$ \\
\hline 18 & $\begin{array}{l}\text { Carboxyphosphonoenol } \\
\text { pyruvate phosphonomutase } \\
\text { (prpB) }\end{array}$ & A1KVK6 & NMC1733 & 73 & 234 & $31876 / 5.22$ & down & $\begin{array}{l}\text { Carbohydrate metabolism: } \\
\text { propanoate metabolism }\end{array}$ \\
\hline 19 & $\begin{array}{l}\text { Putative malonyl Co-A acyl } \\
\text { carrier protein transacylase } \\
(\text { fabD) }\end{array}$ & A1KRY7 & NMC0305 & 57 & 158 & $31958 / 5.44$ & down & $\begin{array}{l}\text { Lipid metabolism: fatty acid } \\
\text { biosynthesis }\end{array}$ \\
\hline 20 & $\begin{array}{l}\text { Septum site-determining } \\
\text { protein (minD) }\end{array}$ & A1KRK2 & NMC0161 & 29 & 143 & $29768 / 5.70$ & down & $\begin{array}{l}\text { Genetic Information } \\
\text { Processing: cell division }\end{array}$ \\
\hline 21 & $\begin{array}{l}\text { Putative two-component } \\
\text { system regulator (NMC0537) }\end{array}$ & A1KSK4 & NMC0537 & 74 & 181 & $24821 / 5.44$ & down & $\begin{array}{l}\text { Environmental Information } \\
\text { Processing: signal } \\
\text { transduction }\end{array}$ \\
\hline 22 & $\begin{array}{l}\text { Peptidyl-prolyl cis-trans } \\
\text { isomerase (ppiB) }\end{array}$ & A1KT50 & NMC0744 & 84 & 260 & $18840 / 5.04$ & down & $\begin{array}{l}\text { Genetic Information } \\
\text { Processing: protein folding }\end{array}$ \\
\hline 23 & $\begin{array}{l}\text { Putative oxidoreductase } \\
\text { (NMC0426) }\end{array}$ & A1KSA1 & NMC0426 & 52 & 129 & 20759/5.74 & down* & - \\
\hline
\end{tabular}

\footnotetext{
${ }^{a}$ According to the UniProtKB/TrEMBL entry http://www.uniprot.org/.

${ }^{b}$ Ordered Locus Name in Neisseria meningitidis serogroup C/serotype 2a (strain ATCC 700532/FAM18).

${ }^{\mathrm{c}}$ Expression level of $\mathrm{RIF}^{\mathrm{R}}$ versus $\mathrm{RIF}^{\mathrm{S}}$ strains.

${ }^{d}$ Functional classification of the proteins according to KEGG: Kyoto Encyclopedia of Genes and Genomes http://www.genome.jp/kegg/.

*Protein with changed pl in RIF ${ }^{\mathrm{R}}$ versus $\mathrm{RIF}^{\mathrm{s}}$ isolate.
} 
NMC0575 and NMC0897 genes of the two resistant strains showed nucleotide mutations resulting in amino acid changes absent in the susceptible strain. All of them were considered missense mutations: 1) an arginine was replaced by a histidine residue at position 21 in the putative oxidoreductase; 2) an aspartic acid was replaced by a glycine residue at position 81 in the putative zinc-binding alcohol dehydrogenase; 3 ) an alanine was replaced by a serine residue at position 331 and an arginine by a leucine at position 351 in the putative phosphate acetyltransferase; 4) a threonine was replaced by an alanine residue at position 166; an isoleucine by a threonine at position 189; a glutamic acid by an alanine at position 212; an aspartic acid by a glycine at position 284; a valine by an alanine at position 710 and a valine by an alanine at position 731 in the isocitrate dehydrogenase.

\section{Analysis of bacteria growth curves}

The rifampicin resistant strains grew normally and showed the same colony appearance as the rifampicin susceptible isolate, on GC agar plates with the naked eye or with a light microscope (data not shown). As shown in figure 2, after GC broth inoculation, there were differences in growth between the susceptible and resistant strains from the starting point of the inoculation (T0) to the stationary phase. In particular, the growth of the resistant strains showed primarily a delay in the onset of the logarithmic phase compared with the susceptible strain with different maximal $\mathrm{OD}_{600}=0.82$ of 1958 , $\mathrm{OD}_{600}=0.7$ of $901, \mathrm{OD}_{600}=0.65$ of 870 (figure 2).

\section{Discussion}

As a transformable bacterium Neisseria meningitidis is incline to acquire exogenous bacterial DNAs, but it has been relatively slow to acquire resistance. However, since it is a severe disease it is very important to monitor changes in the level of antibiotic susceptibility among clinical isolates. Resistance to rifampicin is only occasionally observed but the isolation of a resistant strain poses serious problems in managing the prophylaxis of close contacts. At present, it is unknown how changes in resistant phenotype correspond to different protein expression profiles.

Some studies reveal that the molecular mechanism of resistance is correlated to different amino acid changes in a short central region of the rpoB gene encoding the $\beta$-subunit of the RNA polymerase [3,17]. Moreover, a scarce virulence of rifampicin resistant $N$. meningitidis isolates has been proved in an in vivo model [2].

It is interesting to focus on adaptation mechanisms under antibiotic challenge which have a cost in terms of fitness [18]. The results described in this paper permit to hypothesize that compensation for the rifampicin resistance phenotype may be responsible for the different protein expression in meningococcus. The phenomenon is not so rare among bacterial pathogens and the proteomic approach facilitates the comprehensive

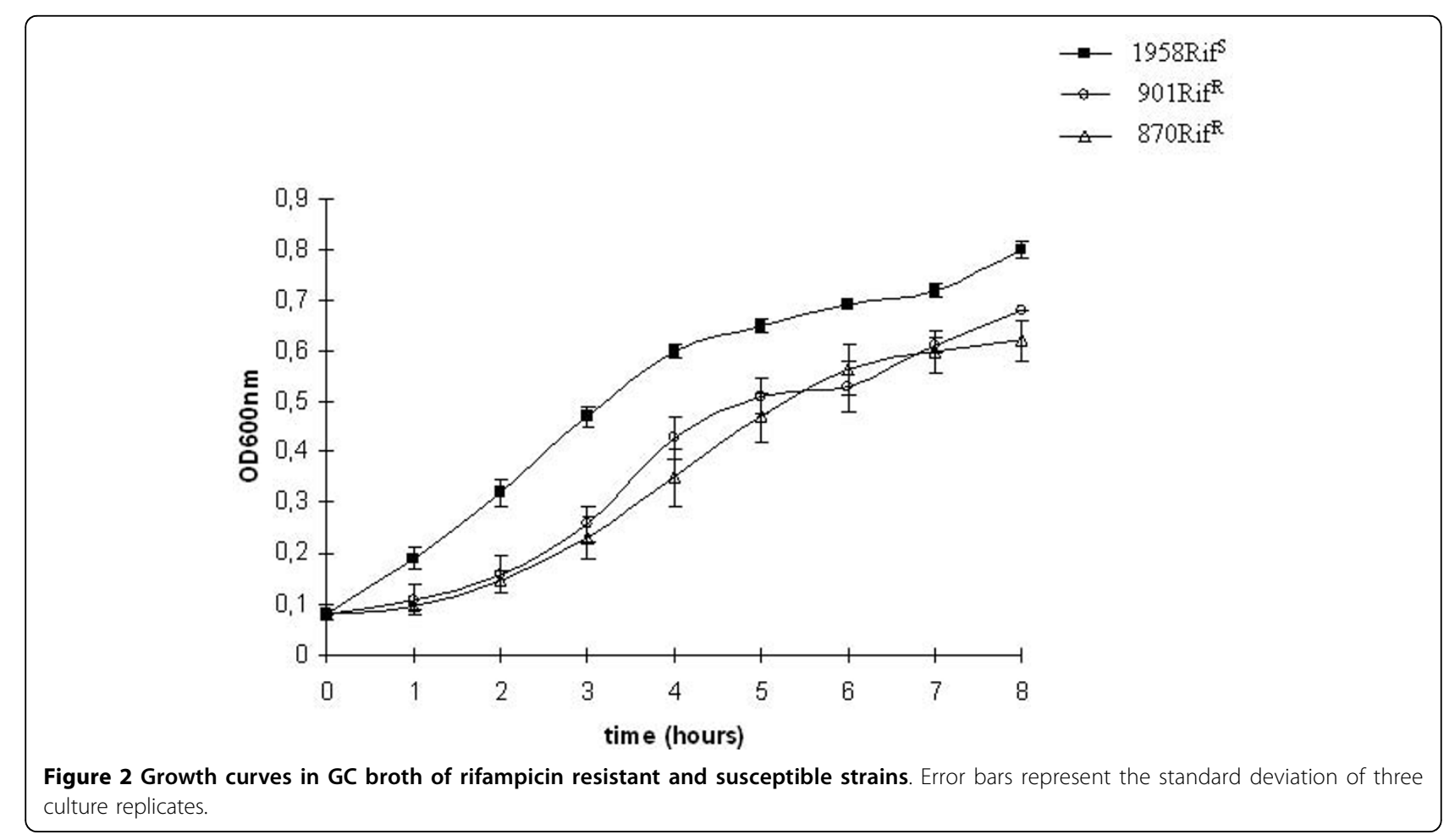


analysis of protein content. Most of the proteins recovered in the 2-DE maps belong to the cytosolic fraction. The latter permits to analyse differences in those proteins involved in metabolic pathways including the RNA polymerase, as the molecular target of rifampicin resistance. On the basis of the catalogue of proteins of the reference $N$. meningitidis strain MC58 [13], protein expression in two rifampicin resistant and one susceptible meningococci was analysed.

The proteomic approach allows us to define the differences in protein pathways compared to the protein set of rifampicin susceptible meningococci.

In our experimental conditions the soluble proteins obtained between pI 4 and 7 were identified in the different set of metabolic pathways. In particular, the results revealed a decrease of proteins, such as the 60 $\mathrm{kDa}$ chaperonin, trigger factor and peptidyl-prolyl cistrans isomerase, involved in the accurate folding of polypeptides. Such results suggest that the bacteria may direct their metabolism towards the production of new polypeptide chains with a high energy cost.

Moreover, the proteins involved in crucial metabolic pathways showed an increased expression with particular regard to the catabolism of the pyruvate: the phosphoenolpyruvate synthase, involved in the conversion of pyruvate into phosphoenolpyruvate, and the pyruvate dehydrogenase subunit E1, that catalyzes the pyruvate decarboxylation into acetyl-CoA. Pyruvate is a key intersection in several metabolic pathways in bacteria [19], and so the altered expression of its catabolites may be reflected in the different pathways it generates. Three proteins, the putative phosphate acyltransferase, the carboxy phosphoenol pyruvate phosphomutase and the putative zinc-binding alcohol dehydrogenase, involved in the TCA cycle, gluconeogenesis and oxidation reaction, were differentially expressed. Similarly to the pyruvate, the acetyl-CoA too is an important molecule in the bacterial metabolism, since it is the starting point of many biochemical reactions [20]. Its main use is to convey the carbon atoms within the acetyl group to the TCA cycle to be oxidized for energy production. In this oxidative direction the two rifampicin resistant isolates showed an up-expression of the three main proteins of the TCA cycle: the aconitate hydratase, the isocitrate dehydrogenase and succinyl-CoA synthetase subunit beta. These results were in agreement with findings in a comparative study on resistant Acinetobacter baumannii [21].

The glutamate dehydrogenase, one of the essential enzymes for meningococcal pathogenesis in the infant rat model [22], was also up-regulated; this is of particular relevance since it belongs to the amino acid biosynthesis.

One of the advantages of the proteomic approach is that protein modifications that lead to changes in charge or size can directly be visualized [23]. In fact, four proteins in both resistant strains displayed a shift in their pI. The pI shifts were confirmed by the presence of amino acid changes due to missense mutations. In particular, the substitution of the cationic amino acid arginine with the neutral leucine was responsible for the acidic shift of putative phosphate acetyltransferase. On the other hand, the basic shift of putative zinc-binding alcohol dehydrogenase and isocitrate dehydrogenase was due to mutations of aspartic acid and glutamic acid to neutral ones. It is noteworthy that the two rifampicin resistant strains showed a different growth curve with a longer lag phase compared to the susceptible isolate. The analysis revealed that most differences in protein expression patterns were genetically encoded rather than induced by antibiotic exposure. Over-expression of stress proteins was expected, as they represent a common non-specific response by bacteria when stimulated by different shock conditions. Positive transcription regulators were found to be over-expressed in rifampicin resistance, suggesting that bacteria could activate compensatory mechanisms to assist the transcription process in the presence of RNA polymerase inhibitors. Other differences in expression profiles were related to proteins involved in central metabolism; these modifications suggest metabolic disadvantages of resistant mutants compared to sensitive ones. Of particular interest are the proteins involved in the cell division site. The altered proteins can affect the integrity of the $\mathrm{Z}$ ring at various stages. In the same way, it was hypothesized that the $\mathrm{Z}$ ring assembly could be both coordinated with the cell cycle and rendered responsive to cellular and environmental stresses.

The analysis of the protein differentially expressed may suggest the intricate series of events occurring in these strains. In this light, the growth results may be partially explained by a decrease expression of proteins such as the cell division protein and the septum sitedetermining protein MinD.

\section{Conclusions}

Our findings reveal that we need a deeper understanding of the interplay between antibiotic resistance, biological fitness and virulence. Although our results are not sufficient to establish an unequivocal association between the differential protein expression and the resistant phenotype, they may be considered a starting point in understanding the decreased invasion capacity of

$N$. meningitidis rifampicin resistant strains. In fact, they support the hypothesis that the presence of more than one protein differentially expressed, having a role in the metabolism, influences the ability to infect and to spread in the population. Different reports have described and 
discussed how a drug resistant pathogen shows a high biological cost for survival $[24,25]$ and that may also explain why, for some pathogens, the rate of resistant organisms is relatively low considering the widespread use of a particular drug. This seems the case of rifampicin resistant meningococci.

Only the combination gained from different experimental methods and clinical data reporting will enable to model the adaptation response of such strains in their physiological network. Our aim was to improve knowledge of the microbial physiology of resistant meningococci and understand why, despite widespread use of rifampicin in prophylactic treatment, the resistant isolates continue to be so rare.

\section{Ethical approval}

Not required.

\section{Acknowledgements}

We thank the microbiologists of the hospital laboratories participating in the Italian Invasive Bacterial Diseases Surveillance Network for isolating the strains and sending them to the Reference Laboratory at the Istituto Superiore di Sanità, Rome, Italy. The authors are grateful to Dr. Paola Mastrantonio as director of the Reference Laboratory for Invasive Bacterial Diseases for helpful discussion. We thank Tonino Sofia for editorial assistance. This work was partially funded by the Ministry of Health-CCM Project 116 "Surveillance of invasive bacterial diseases", 2007-2009 and by the Ministry of Education, University and Research (MIUR) to G. M 2008-2009.

\section{Author details}

${ }^{1}$ Department of Infectious, Parasitic and Immune-mediated Diseases, Istituto Superiore di Sanità, Viale Regina Elena 299, 00161 Rome, Italy. ${ }^{2}$ Department of Biochemical Sciences, "A. Rossi Fanelli", University "Sapienza", Piazzale Aldo Moro 5, 00185 Rome, Italy.

\section{Authors' contributions}

AN performed protein extractions from the strains and drafted the manuscript. CF characterized the strains. GM and AG performed the 2-DE and mass spectrometry experiments, the statistical analysis and helped in the manuscript revision. MES contributed the final 2-DE analysis. PS conceived the study, designed and supervised the work and edited the manuscript. All authors read and approved the final manuscript.

\section{Competing interests}

The authors declare that they have no competing interests.

Received: 30 April 2010 Accepted: 24 September 2010 Published: 24 September 2010

\section{References}

1. Rainbow J, Cebelinski E, Bartkus J, Glennen A, Boxrud D, Lynfield R: Rifampin-resistant meningococcal disease. Emerg Infect Dis 2005, 11:977-979.

2. Taha MK, Zarantonelli ML, Ruckly C, Giorgini D, Alonso JM: Rifampinresistant Neisseria meningitidis. Emerg Infect Dis 2006, 12:859-860.

3. Carter PE, Abadi FJ, Yakubu DE, Pennington TH: Molecular characterization of rifampin-resistant Neisseria meningitidis. Antimicrob Agents Chemother 1994, 38:1256-1261.

4. Nolte O: Rifampicin resistance in Neisseria meningitidis: evidence from a study of sibling strains, description of new mutations and notes on population genetics. J Antimicrob Chemother 1997, 39:747-755.

5. Stefanelli P, Fazio C, La Rosa G, Marianelli C, Muscillo M, Mastrantonio P. Rifampicin-resistant meningococci causing invasive disease: detection of point mutations in the rpoB gene and molecular characterization of the strains. J Antimicrob Chemother 2001, 47:219-222.

6. Skoczynska A, Ruckly C, Hong E, Taha MK: Molecular characterization of resistance to rifampicin in clinical isolates of Neisseria meningitidis. Clin Microbiol Infect 2009, 15:1178-1181.

7. Abadi FJ, Carter PE, Cash P, Pennington TH: Rifampin resistance in Neisseria meningitidis due to alterations in membrane permeability. Antimicrob Agents Chemother 1996, 40:646-651.

8. Pan W, Spratt BG: Regulation of the permeability of the gonococcal cell envelope by the $m$ tr system. Mol Microbiol 1994, 11:769-775.

9. Hagman KE, Pan W, Spratt BG, Balthazar JT, Judd RC, Shafer WM: Resistance of Neisseria gonorrhoeae to antimicrobial hydrophobic agents is modulated by the mtrRCDE efflux system. Microbiology 1995, 141(Pt 3):611-622.

10. Rouquette-Loughlin CE, Balthazar JT, Hill SA, Shafer WM: Modulation of the

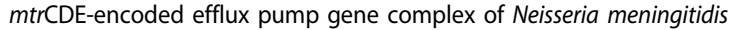
due to a Correia element insertion sequence. Mol Microbiol 2004, 54:731-741.

11. Wang $Q$, Yue J, Zhang $L, X u Y$, Chen J, Zhang M, Zhu B, Wang H: A newly identified 191A/C mutation in the Rv2629 gene that was significantly associated with rifampin resistance in Mycobacterium tuberculosis. $J$ Proteome Res 2007, 6:4564-4571.

12. Bernardini G, Braconi D, Santucci A: The analysis of Neisseria meningitidis proteomes: Reference maps and their applications. Proteomics 2007, 7:2933-2946.

13. Mignogna G, Giorgi A, Stefanelli P, Neri A, Colotti G, Mara B, Schinina ME: Inventory of the proteins in Neisseria meningitidis serogroup B strain MC58. J Proteome Res 2005, 4:1361-1370.

14. Perkins DN, Pappin DJ, Creasy DM, Cottrell JS: Probability-based protein identification by searching sequence databases using mass spectrometry data. Electrophoresis 1999, 20:3551-3567.

15. Pappin DJ: Peptide mass fingerprinting using MALDI-TOF mass spectrometry. Methods Mol Biol 2003, 211:211-219.

16. Wu CH, Apweiler R, Bairoch A, Natale DA, Barker WC, Boeckmann B, Ferro S, Gasteiger E, Huang H, Lopez Magrane M, Martin MJ, Mazumder R, O'Donovan C, Redaschi N, Suzek B: The Universal Protein Resource (UniProt): an expanding universe of protein information. Nucleic Acids Res 2006, 34:D187-D191.

17. Nolte O, Muller M, Reitz S, Ledig S, Ehrhard I, Sonntag HG: Description of new mutations in the $r p \circ B$ gene in rifampicin-resistant Neisseria meningitidis selected in vitro in a stepwise manner. J Med Microbiol 2003, 52:1077-1081.

18. Andersson DI, Levin BR: The biological cost of antibiotic resistance. Curr Opin Microbiol 1999, 2:489-493.

19. Sauer U, Eikmanns BJ: The PEP-pyruvate-oxaloacetate node as the switch point for carbon flux distribution in bacteria. FEMS Microbiol Rev 2005, 29:765-794

20. El-Mansi M, Cozzone AJ, Shiloach J, Eikmanns BJ: Control of carbon flux through enzymes of central and intermediary metabolism during growth of Escherichia coli on acetate. Curr Opin Microbiol 2006, 9:173-179.

21. Fernandez-Reyes M, Rodriguez-Falcon M, Chiva C, Pachon J, Andreu D, Rivas L: The cost of resistance to colistin in Acinetobacter baumannii: a proteomic perspective. Proteomics 2009, 9:1632-1645.

22. Sun YH, Bakshi S, Chalmers R, Tang CM: Functional genomics of Neisseria meningitidis pathogenesis. Nat Med 2000, 6:1269-1273.

23. Hecker M, Antelmann H, Buttner K, Bernhardt J: Gel-based proteomics of Gram-positive bacteria: a powerful tool to address physiological questions. Proteomics 2008, 8:4958-4975.

24. Andersson DI: Persistence of antibiotic resistant bacteria. Curr Opin Microbiol 2003, 6:452-456.

25. Handel A, Regoes RR, Antia R: The role of compensatory mutations in the emergence of drug resistance. PLoS Comput Biol 2006, 2:e137.

doi:10.1186/1471-2180-10-246

Cite this article as: Neri et al:: Neisseria meningitidis rifampicin resistant strains: analysis of protein differentially expressed. BMC Microbiology 2010 10:246. 